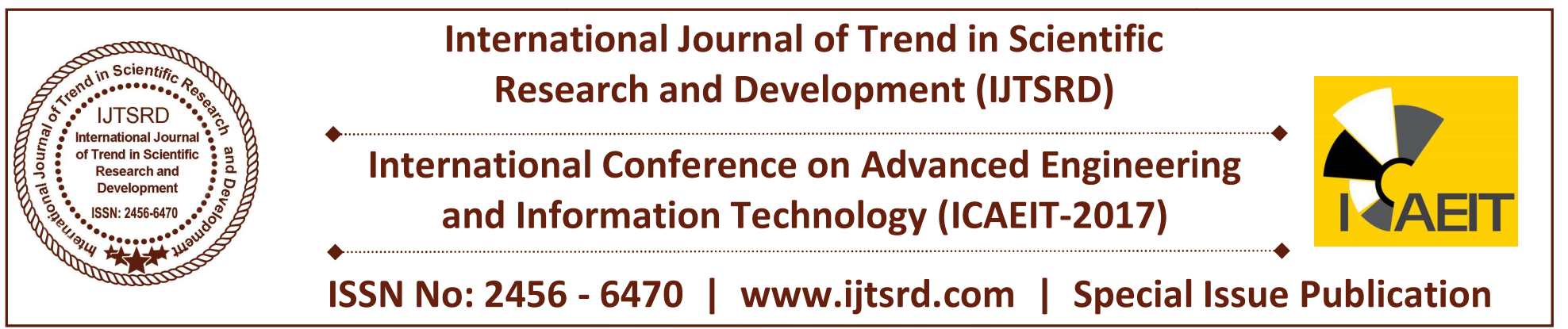

\title{
Early Childhood Education Smart Web Portal Using Intelligence Information Systems
}

\author{
Mohamad Zafranudin Bin Mohamed Zafrin ${ }^{1}$, Subashini A/P Ganapathy ${ }^{2}$, Sajitha Smiley ${ }^{3}$ \\ ${ }^{1}$ Linton University College in collaboration with Leeds Beckett University, Negeri Sembilan, Malaysia \\ ${ }^{2}$ FOET, Linton University College, Negeri Sembilan, Malaysia \\ ${ }^{3}$ SEEMIT, Institut Teknologi Pertama, Negeri Sembilan, Malaysia
}

\begin{abstract}
Pre-school students are still very dependent on their parents with regards to school matters. This is the reason why there should be a very close communication between the teacher and the parents. In this age where instant messaging or instant video call is just a click away, it is very easy to snap a picture or make a report of the activities of the students and send them to the parents. A smart portal is in line for this system. The paper proposes that a smart web portal be developed in intelligent information system (IIS) for early childhood education as a way of increasing the effectiveness for the parents to get information or knowledge about the day to day activities of their pre-school children and to empower teachers to use ICT tools. Smart web portal for early childhood education using intelligence information system is a new way to distribute knowledge of information resources within the stakeholders of the organization such as the parents, teachers and the students. The development of a smart web portal to be used for an early childhood school is explored and proposed using IIS.
\end{abstract}

Keywords: Early-childhood education, smart web portal development, intelligence information system

\section{INTRODUCTION}

Early childhood education is deemed one of the most important part in a person's educational life. The reason is because this is the diving board for a person in his journey to learning. Parents usually make a fuss during their children's pre-school learning not only because this is the first educational experience of their child but because this will mark the rest of their learning path. For an entire nation, giving investment in the early years is one of the best things they can do to reduce great poverty, boost shared prosperity, and create the human capital needed for economies to diversify and grow. It has been observed that early childhood experiences have a deep impact on the development of the brain. It would affect learning, health, behavior and later on also income. An increasingly digital economy places even greater premiums on the ability to reason, continually learn, effectively communicate and collaborate. Those who lack these skills will be left further behind [1].

Early childhood education (ECE) is an expansive term used to define different kinds of educational programs that cater to children in their preschool years. This is before entering kindergarten. ECE may comprise of programs with a number of activities and experiences developed to assistance in the cognitive and social development of preschoolers prior to entering elementary school [2].

Preschool education programs are designed especially for children between three to five-year olds, and they may be provided in childcare and daycare or nursery school settings, as well as more conventional preschool or pre- kindergarten classrooms. Pre-school programs are housed in different venues such as center-based, home- based, or public school settings.

Kanter [3] defined preschool as referring to an earlychildhood educational class for 3- and 5-year-olds. A 
lot of the classes are part-time, around 3 to 5 hours a day, two to five times a week, and also full day care.

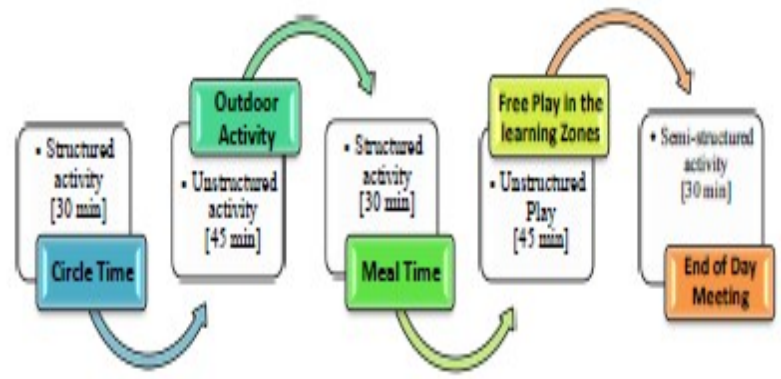

Figure 1: Typical daily activities in pre-school. Source: [5]

Because of the growing usage of the internet, and the vast information that are being used and created each day, these have become reasons for development or research on various techniques and method on processing and analysis of data. One of these developments is in intelligent information systems, where speech recognition, search engines, machine translation, machine learning are included. Besides that, the modern intelligence system had different components of software in them in order to simulate the human intelligence [4].

The wide use of information and communications technology (ICT) in education has prompted ECE to also explore ways in which ICT can be of support to this area of education. Hammed [5] pointed out some roles of ICT as integrated in ECE, and they are: Preschool students using ICT in play or in learning, either alone or with schoolmates and teachers; pre-school students and educators using ICT to enhance pedagogy; pre-school students and educators using ICT to document and assess on the student's learning and to share these information to parents or to other educators; educators using ICT for planning, administration and in management of education; preschool students and educators using ICT to communicate or share information with parents, or other educators.

This paper will consider these roles of ICT in ECE in the design and development of a smart web portal using IIS.

\section{Smart Web Portal Development}

Smart web portals are alternative forms of online intelligence information system (IIS). It is a gateway which distributes knowledge of information resources that is highly relevant to the area of application. The query extension and specific user model is capable of dynamically meeting the individual needs. In smart web portal, information added about the authority, provenance, reliability, and quality of the information resources which can be accessed via the portal. Combination of the smart information technologies with the user sensitive approach may provide knowledge regarding the quality or quantity of online information.

These portals are capable of executing three main functions: gathering (collecting) information from different sources, analyzing (processing) collected information and disseminating analyzed information. Thus, the Smart Web Portal system will be comprised of the following modules: 1. Collection Module generates relation between intelligence information and stores data from different sources; 2. Processing Module - updates and enriches knowledge database; 3. Dissemination Module - creates and stores users, and updates existed user profiles.

Smart web portal has emerged for several efficient use of managing data and the functionality by collecting and analyzing large scale information and turning it into useful knowledge for the user, rather than the user compiling all the gathered information and turning it into knowledge [6].

By determining the content and the web specification, the smart web portal system allows users to gain knowledge of the website provided instead of just information of the website. With this, it can be described as an effectiveness of providing knowledge of the website to the user and allowing the user to understand what the specific website is all about.

The idea is using IIS and applying it to web portal development to ensure functionality, efficiency, usability, reliability and also maintainability of the web portal. In short, the goal of the research is to determine if smart web portal that are developed in a way which allow users to receive the knowledge they need are more effective instead of smart web portal that provide only information where user have to convert that information into a useful knowledge.

\section{Intelligence Information System (IIS)}

Keeping in mind the end goal to see more about insight data framework, above all else is to comprehend from the fundamental which is the information system (IS). Data framework is a 
framework which is sorted out so as to gather, compose, store and furthermore the correspondence of data. Information systems (IS) create data by the connection of assembled segments [6]. With a specific end goal to execute the possibility of a wise capacity into data frameworks is to control how the data is gathered, sorted out, put away. With regards to keen web-based interface, these capacities have been executed in, for example, programmed message or email activated by a few occasions. This could go about as an update or as a notice for customers as there would be security issue or other issues.

There are different types of information system such as expert systems, search engines, geographical information system and more. In the area of computer science, the idea of machines or software that can react, understand, thinking like a human and selfimprovement is certainly important for technology advancement. As the keywords "Smart web portal development" and "Intelligence Information System" suggest, the idea generally would be the use of artificial intelligence in web applications.

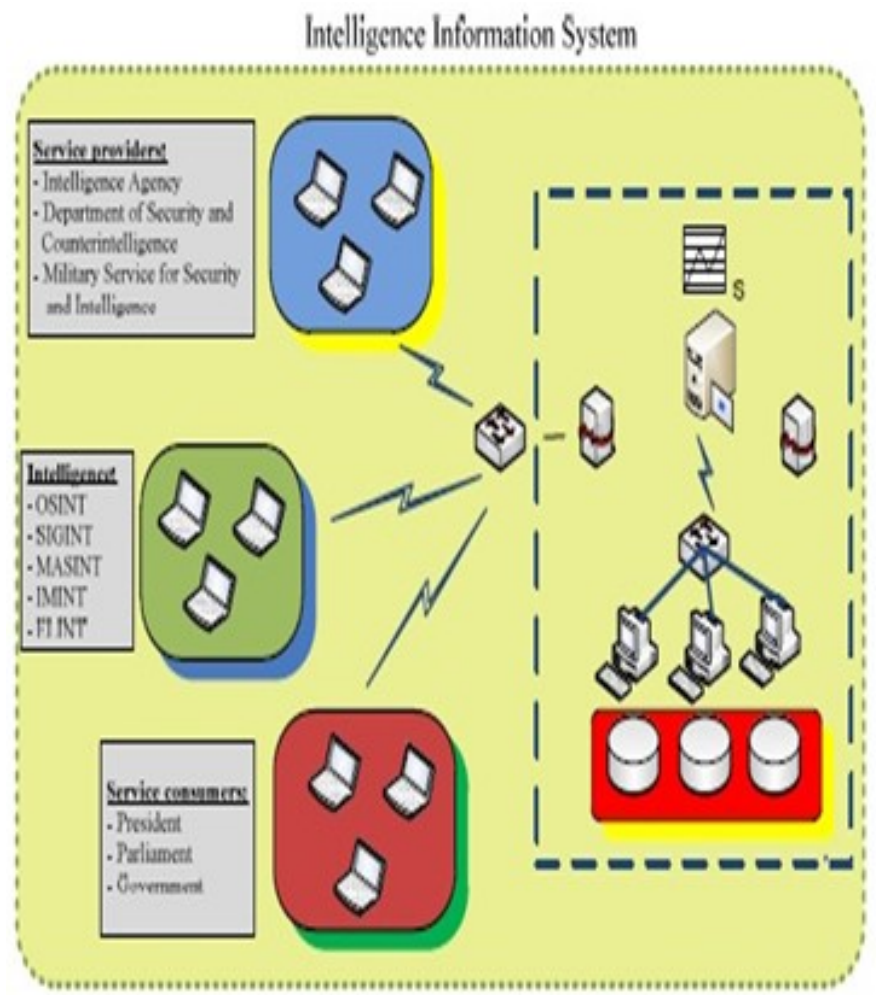

Figure 2: Intelligence Information System. Source: [4]

Using artificial intelligence in the area of web application and web portal have been implemented by popular social network website such as Facebook or search engine website such as Google. For example,
Facebook's use of AI in their recognition of human face, it functions as a recommendation where the AI learn which face are tagged with identified friend more often over time and this allow the AI to identify the person more accurately [7].

Although there are not much web portal developments that include IIS, but certainly some of web portal have proven to be effective in either improvement or others. Systems that allow city authorities know which services who voted satisfy or unsatisfied by the citizen and this allow direct feedback to be given to the city authorities [8]. By using the developed smart web portal, it will allow cities to gather data from citizens directly for further analysis and service improvements.

\section{Proposed Smart Web Portal for Early Childhood Education}

"There's increasing evidence that children gain a lot from going to preschool," this is according to Parents advisor Dr. Kathleen McCartney, the dean of Harvard Graduate School of Education, Massachusetts, USA. She added that in preschool, students are exposed to numbers, letters, and shapes. But, according to her, the more important thing is that they learn socialization, how to get along with their fellow children, to be able to share, and to contribute to circle time [3].

Accordingly, statistics show that a majority of kids attend at least one year of preschool, according to the National Institute for Early Education Research (NIEER). "Children who attend high-quality preschool enter kindergarten with better pre-reading skills, richer vocabularies, and stronger basic math skills than those who do not," says NIEER director W. Steven Barnett, PhD [3].

An ECE organization will need a school management system to help teachers to increase productivity and foster better and more effective communication between the educators, administrators and parents. This is the objective of the Smart Web Portal for Early Childhood Education that this paper is exploring. Along with that, it is also an objective of the paper to empower the educators of ECE with ICT solutions to lessen their workload through paperless documentation and communication. Added to that, it will also enhance learning experiences of the ECE students. 
The proposal will include a design and development of a Smart Web Portal that will have the following functionalities:

1. Registration and Administration of the portal. An administrator will be able to handle registration to the system and other administrative tasks

2. Management of information, content and records of all stakeholders of the organization but most importantly, students and teachers, including fees and other business contents.

3. Data storage for all records, information, teaching and learning materials that are needed in the pedagogical function of the organization.

4. A knowledge-base to support decision-making for the educators and managers of the organization.

5. Communication systems, email, messaging, broadcast system between the parents and/or students and the teachers and administrators.

6. Monitoring system for parents to keep track of their children's progress.

7. Report generation for attendance, portfolios, academic and health records of all stakeholders.

8. A mobile application that will support parents whenever they want to monitor their children anytime of the day, also to receive notifications as updates of class activities, and to view them in interfaces that are user friendly.

Besides providing all the necessary functionalities that they need, the productivity of each early-childhood organization can also be increased by taking advantage of new communications technology to better notify each entities for different productive use cases.

\section{Conclusion}

This study has explored the use of smart web portal using intelligence information systems and to be applied to an early childhood education institution. It also proposes the development of a smart web portal using intelligence information system. A smart web portal will increase the functionalities of a typical preschool education management system. The idea of smart web portal development in intelligence information system where the different techniques of automated information collecting, organizing, storing and communicating would increase the effectiveness of the smart web portal as applied to the ECE area. These concepts are basically where the information is stored in the database of collection and then it will be transformed into various types of data such as the text, video, or even audio and shared effectively.

\section{Recommendations}

The design, development and implementation of a smart portal for early childhood development using intelligence information system is recommended since it is confirmed in this paper that it is very much probable and effective. The stakeholders (parents, teachers and students) of an ECE will definitely benefit with a smart web portal as was pointed out in the above discussions. More in-depth research is needed in the profitability and business concept should be done in the development of smart web portals using IIS.

\section{References}

1. "Early Childhood Development", World Bank, 2017. [Online]. Available: http://www.worldbank.org/en/ topic/earlychildhooddevelopment. [Accessed: 06Nov-2017].

2. "What is Early Childhood Education | What is a Preschool Teacher", Preschoolteacher.org, 2017. [Online]. Available: https://www.preschoolteacher.org/what-is-earlychildhood-education/. [Accessed: 01- Nov- 2017].

3. B. Kanter, "Why Preschool Matters", Parents, 2017. [Online]. Available: http://www.parents.com/toddlerspreschoolers/starting-preschool/curriculum/whypreschool-matters/. [Accessed: 02- Nov- 2017].

4. J. Achkoski, V. Traikovic, N. Serafimova, (2012). A Concept for a Smart Web Portal Development in Intelligence Information System Based on SOA. The 9th Conference for Informatics and Information Technology (CIIT 2012), Skopje, Macedonia.

5. N. Hammed, (2013), "Information and Communication Technology in Early Childhood Education: Challenges for Effective Implementation and Integration", College of Social Sciences, University of Glasgow.

6. D. Kroenke, (2015), MIS Essentials (Fourth ed.) Boston; Pearson, p.10.

7. J. Kelly (2016), What websites use artificial intelligence? - Quara. [online]. Available at http://www.quora.com/What-websites-useartificial- intelligence. Accessed: 01 November 2017.

8. D. O’Neil, C. Peoples (2017), A Web-based Portal for Assessing Citizen Well-Being. Ulster University, UK. 